ats

Original

\title{
Frecuencia serológica de Neospora caninum en unidades de producción en zona central de Veracruz, México
}

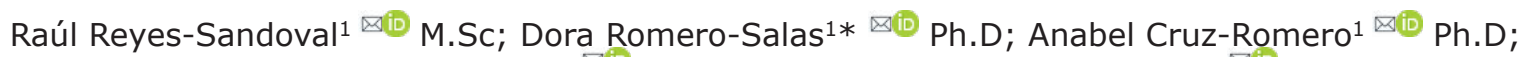 \\ Jenny Chaparro-Gutiérrez ${ }^{凶} \mathbb{0}$ Ph.D; Miguel Lammoglia-Villagómez ${ }^{3}{ }^{凶}$ Ph.D; \\ Karla López-Hernández ${ }^{\circledR(\mathbb{D}}$ Ph.D; Juan Ojeda-Carrasco ${ }^{凶}{ }^{凶}$ Ph.D.
}

\begin{abstract}
${ }^{1}$ Universidad Veracruzana, Facultad de Medicina Veterinaria y Zootecnia, Rancho Torreón del Molino, Unidad de Diagnóstico, Laboratorio de Parasitología, Veracruz, México.

¿Universidad de Antioquía, Facultad de Ciencias Agrarias, Grupo de Investigación CIBAV, Medellín, Colombia.

3Universidad Veracruzana, Facultad de Ciencias Biológicas y Agropecuarias, Tuxpan, Veracruz, México.

«Universidad Autónoma del Estado de México, Centro Universitario UAEM Amecameca, Licenciatura en Medicina Veterinaria y Zootecnia, Amecameca, Estado de México, México.

*Correspondencia: dromero@uv.mx
\end{abstract}

Recibido: Junio 2020; Aceptado: Marzo 2021; Publicado: Mayo 2021.

\section{RESUMEN}

Objetivo. Determinar la frecuencia de Neospora caninum en dos Unidades de Producción Pecuaria con sistema búfalo/bovino de la zona central del estado de Veracruz, México. Materiales y Métodos. Fue un estudio de tipo transversal con muestreo no probabilístico por conveniencia. Se incluyeron dos Unidades de Producción Pecuaria (UPP), ambas con población bufalina y bovina ubicadas en la zona central del estado de Veracruz, México. Se incluyó el total de la población bufalina, bovina y canina, tomando muestras sanguíneas entre febrero-marzo, 2019, las cuales fueron procesadas con la prueba comercial ELISA (IDEXX ${ }^{\circledR}$ ) y la prueba de inmunofluorescencia indirecta (VMRD, Pullman, WA, USA). En cada UPP, se aplicó una encuesta general y una individual para la colecta de datos. Los resultados se analizaron con el software STATA versión 14.0. Resultados. Del total de la población bóvida analizada, 63/138 animales presentaron anticuerpos contra $N$. caninum con frecuencia de $45.6 \%\left(\mathrm{IC}_{95 \%} 37.1-54.3\right)$. Con relación a las UPP, la población de búfalos presentó mayor presencia de anticuerpos contra $N$. caninum, $26 / 31$ de la UPP Cotaxtla con $83.8 \%$ (IC $_{95 \%} 66.2-94.5$ ) y $12 / 22$ de la UPP Medellín con 54.5\% ( IC $_{95 \%} 32.2-75.6$ ). Con relación a los perros, $4 / 6$ resultaron positivos (66.6\%). Se observó que de acuerdo con la especie animal 38/53 búfalos, presentaron la mayor

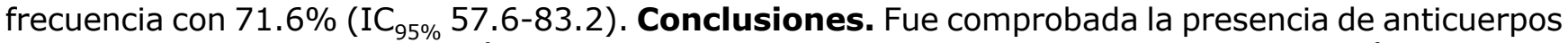
contra $N$. caninum en población bovina y bufalina de las UPP estudiadas. Se confirmó que existe una mayor frecuencia de anticuerpos en búfalos de agua cuando cohabitan con bovinos y caninos.

Palabras clave: Búfalo de agua; control; inmunidad; protozoario (Fuente: MeSH).

\section{ABSTRACT}

Objective. To determine the frequency of Neospora caninum in two Livestock Production Units with a buffalo/bovine system in the central zone of the state of Veracruz, México. Materials and methods. It was a cross-sectional study with non-probability convenience sampling. Two Livestock

Como citar (Vancouver).

Reyes-Sandoval RM, Romero-Salas D, Cruz-Romero A, Chaparro-Gutiérrez JJ, Lammoglia-Villagómez MA, López-Hernández KM, Ojeda-Carrasco JJ. Frecuencia serológica de Neospora caninum en Unidades de Producción en zona central de Veracruz, México. Rev MVZ Córdoba. 2021; 26(3):e2135. https://doi.org/10.21897/rmvz.2135 
Production Units (UPP), both with buffalo and bovine populations located in the central zone of the state of Veracruz, México were included. The total population of buffalo, bovine and canine were included, the blood samples were taken between February-March, 2019, and were processed with a commercial ELISA test (IDEXX ${ }^{\circledR}$ ) and an Indirect Immunofluorescence Test (VMRD, Pullman, WA, USA). In each UPP, a general and individual survey was applied to collect data. The results were analyzed with STATA software version 14.0. Results. 68 samples out of 138, presented antibodies against $N$. caninum with a frequency of $45.6 \%$ (95\%CI 37.1-54.3). In relation to UPP, the buffalo population had a higher presence of antibodies against $N$. caninum, 26/31 from UPP Cotaxtla with $83.8 \%$ (95\%CI 66.2-94.5) and 12/22 from UPP Medellín with 54.5\% (95\%CI 32.2-75.6). In relation to dogs, $4 / 6$ were positive (66.6\%). It was observed that according to the animal species $38 / 53$ buffaloes, presented the highest frequency with $71.6 \%$ (95\%CI 57.6-83.2). Conclusions. The presence of antibodies against $N$. caninum in the bovine and buffalo population of the studied UPPs was verified. It was confirmed that there is a higher frequency of antibodies in water buffaloes when they cohabit with cattle and canines.

Keywords: Water buffalo; control; immunity; protozoan (Source: MeSH).

\section{INTRODUCCIÓN}

Neospora caninum es un protozoario parásito que puede infectar una amplia gama de animales de sangre caliente, provocando alteraciones reproductivas en bovinos, pequeños rumiantes y algunas especies silvestres, así como serios padecimientos neurológicos en caninos (1). La neosporosis representa la principal causa de fallo reproductivo y aborto en poblaciones bovinas susceptibles a nivel mundial, causando grandes pérdidas económicas de manera especial en bovinos (2), en los cuales la infección se transmite vía transplacentaria, además de reducir la producción cárnica y láctea (3).

El ciclo de vida de $N$. caninum incluye a caninos como hospederos definitivos y a rumiantes como hospederos intermediarios; se cree que un ciclo entre cánidos silvestres como coyotes y perros ferales juega un papel importante en la biología de $N$. caninum (4). A pesar de que la exposición a $N$. caninum se ha demostrado en una gran variedad de especies domésticas y silvestres, sólo se han aislado parásitos viables de un limitado número de éstas, incluyendo a bovinos, venados cola blanca, ovejas y búfalos de agua (2).

El búfalo de agua (Bubalus bubalis) es considerado actualmente un animal de gran auge en todo el mundo debido a su adaptabilidad y rusticidad. Su importancia económica radica en que es un animal de triple propósito, ya que puede producir leche, carne y ser usado como animal de tracción (5). El número de búfalos de agua en el mundo ha aumentado de manera rápida en las últimas décadas y, según las estadísticas de la Organización de las Naciones Unidas para la Alimentación y la Agricultura (FAO) en la actualidad hay alrededor de 195 millones de búfalos en el mundo (6), estos animales han demostrado tener una gran capacidad de adaptación y pueden subsistir donde otros animales no pueden hacerlo, pues han logrado mantenerse en ambientes tan variados como los de Australia, Brasil, Rusia y Nepal (7), encontrándose en zonas con temperaturas que oscilan desde $0^{\circ} \mathrm{C}$ hasta $45^{\circ} \mathrm{C}$, en terrenos llanos o montañosos, en climas templados, secos y tropicales lluviosos (8).

Se ha demostrado que el búfalo de agua es susceptible a la infección por $N$. caninum, ya sea de manera natural o experimental (9). Gracias a su importancia económica en la industria ganadera internacional se han dirigido diferentes estudios para conocer la seroprevalencia frente a $N$. caninum en estos animales alrededor del mundo, y debido a las dificultades para diagnosticar la neosporosis clínica, las pruebas serológicas son necesarias y útiles para la detección de anticuerpos (3).

A pesar de que la enfermedad ha sido ampliamente estudiada a nivel internacional en búfalos y bovinos por separado, son limitados los estudios dirigidos para conocer la situación epidemiológica cuando ambas especies comparten el mismo espacio. En México son pocos los estudios encaminados a conocer la situación epidemiológica de $N$. caninum en búfalos y hasta el momento no existen reportes de este agente en Unidades de Producción Pecuaria (UPP) donde cohabitan ambas especies. En este contexto, el objetivo del presente estudio fue determinar la frecuencia de Neospora caninum en dos Unidades de Producción Pecuaria con sistema búfalo/bovino de la zona central del estado de Veracruz, México. 


\section{MATERIALES Y MÉTODOS}

Tipo de estudio. Fue un estudio de tipo transversal con muestreo no probabilístico por conveniencia.

Localización. Se incluyeron dos Unidades de Producción Pecuaria (UPP) con población bovina y bufalina, ubicadas en la zona central del estado de Veracruz, México. La UPP1, se ubica en el

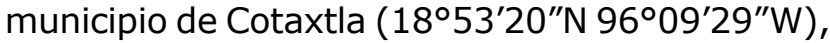
a una altura de $40 \mathrm{msnm}$, tiene clima cálidoseco-regular con temperatura promedio de $26^{\circ} \mathrm{C}$; su precipitación pluvial media anual es de 1,900 mm (10). La UPP2, se ubica en el municipio de

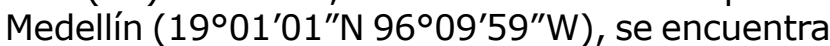
a $52 \mathrm{msnm}$, su clima es cálido-húmedoextremoso con una temperatura promedio de $25.3^{\circ} \mathrm{C}$, su precipitación pluvial media anual es de $1417.8 \mathrm{~mm}$ (10).

Características de los hatos. En la UPP1, los bóvidos (bovinos y búfalos de agua) se mantienen en producción extensiva en potreros con pasto Pará (Urochloa mutica), Mombaza (Panicum maximum) y grama nativa, con rotación mensual en el caso de los bovinos, los búfalos permanecen en el mismo potrero por periodos de 4 a 6 meses y sin ningún tipo de suplementación para ambas especies. Únicamente los bovinos son sometidos a programa de vacunación (Bacterina 11 Vías, Bio zoo, Jalisco, México) y desparasitación anual (Ivermectina, Boehringer Ingelheim, Jalisco, México; Albendazol, Zoetis, CDMX, México).

En la UPP2, los bóvidos (bovinos y búfalos de agua) se mantienen en producción extensiva en potreros con pasto estrella (Cynodon plectostachyus) y grama nativa con rotación mensual, suplementan su alimentación con desecho de elote (maíz) y sales minerales. Solamente los bovinos se someten a un programa de vacunación (Bacterina 11 Vías, Adler, Jalisco, México) y desparasitación semestral (Ivermectina, Virbac, Jalisco, México).

Toma de muestras. En ambas UPP, se incluyó el total de la población bufalina, bovina y canina al momento del muestreo. En la UPP1 se incluyeron 31 búfalos (tres machos, 28 hembras con edades de 4 a 120 meses, todos de fenotipo Murrah), 50 bovinos (cuatro machos, 46 hembras con edades de 0.3 a 132 meses, todos de fenotipo cruza) y cuatro caninos (dos hembras, dos machos de 3 a 36 meses de fenotipo criollo); en la UPP2 se muestrearon 22 búfalos (ocho machos, 14 hembras con edades de 3 a 96 meses, todos con fenotipo Murrah), 35 bovinos ( 7 machos, 28 hembras, con edades de 1 a 121 meses, todos de fenotipo Beef master) y dos caninos (1 macho, 1 hembra, con edades de 24 y 36 meses de fenotipo criollo). Se tomaron muestras sanguíneas entre febrero y marzo de 2019 con equipo de vacío sin anticoagulante por punción de las venas yugular, caudal o cefálica de acuerdo con la especie, para la separación de suero las muestras se centrifugaron a $1000 \mathrm{~g}$ durante 10 minutos y fueron almacenados a $-20^{\circ} \mathrm{C}$ hasta su posterior análisis.

Análisis serológico. Para el diagnóstico serológico en los bovinos y búfalos de agua se utilizó la prueba ensayo inmunoabsorbente ligado a enzimas (ELISA) para la identificación de anticuerpos IgG contra $N$. caninum, se utilizó un kit comercial de la marca IDEXX ${ }^{\circledR}$-Laboratories (Sensibilidad $98.6 \%$ y Especificidad de $98.9 \%$ ), siguiendo las especificaciones del fabricante; la lectura de las placas se realizó con un espectrofotómetro de la marca Bio-Rad ${ }^{\circledR}$ modelo 680 , se midió la densidad óptica y longitud de onda con un filtro de $650 \mathrm{~nm}$. En el caso de los sueros caninos se utilizó un paquete comercial de la prueba de inmunofluorescencia indirecta (IFA, VMRD, Pullman, WA, USA) siguiendo las recomendaciones del fabricante.

Variables. En cada UPP, se aplicó una encuesta general y una individual para la colecta de datos como: especie, edad, sexo, condición corporal (donde 1 es emaciado y 5 con sobrepeso), nacido en la UPP, vacunación, fuente de agua (corriente o represa) y densidad (animales/hectárea), entre otras. Las variables tomadas en cuenta han sido mencionadas como factores de riesgo para presencia de anticuerpos anti- $N$. caninum anteriormente $(1,9,12)$.

Análisis estadístico. Los resultados se analizaron con la ayuda del software STATA versión 14.0. Se calculó la frecuencia. La asociación de infecciones con datos generales de las UPP, bovinos y búfalos se analizó por $X^{2}$, se calcularon los intervalos de confianza IC al $95 \%$. Los valores de $p<0.05$ se consideraron estadísticamente significativos. Un rancho se consideró positivo cuando al menos un animal presentó anticuerpos contra $N$. caninum.

Aspectos éticos. El protocolo de trabajo contó con la aprobación de la Comisión de Bioética y Bienestar Animal de la Facultad de Medicina Veterinaria y Zootecnia de la Universidad Veracruzana, acorde con la NOM -062-ZOO-1999 (11). 


\section{RESULTADOS}

Se detectaron anticuerpos en ambas UPP estudiadas y en las tres especies analizadas. La Tabla 1, muestra que, del total de la población analizada en ambas UPP, 63/138 animales presentaron anticuerpos contra $N$. caninum con una frecuencia de $45.6 \%\left(\mathrm{IC}_{95 \%} 37.1-54.3\right.$ ). Con relación a la UPP 1 , ubicada en Cotaxtla, 40/81 animales resultaron seropositivos con el $49.3 \%\left(\right.$ IC $\left._{95 \%} 38.1-60.6\right)$ y en la UPP 2, ubicada en Medellín, 23/57 animales resultaron seropositivos con $40.3 \%$ ( $\left.\mathrm{IC}_{95 \%} 27.8-54.1\right)$. La población de búfalos fue la que resultó con mayor presencia de anticuerpos contra $N$. caninum,

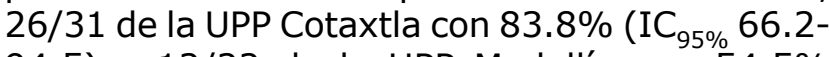
94.5) y $12 / 22$ de la UPP Medellín con $54.5 \%$ $\left(\mathrm{IC}_{95 \%} 32.2-75.6\right)$.

Tabla 1. Frecuencia de Neospora caninum en Bovinos y Búfalos de Agua por Unidad de Producción Pecuaria.

\begin{tabular}{ccccccc}
\hline Variable & $\mathbf{n}$ & + & $\mathbf{F \%}$ & ${ }^{*} \mathbf{I C}_{\mathbf{9 5} \%}$ & $\mathbf{X}^{\mathbf{2}}$ & $\mathbf{P}$ \\
\hline UPP 1 & Cotaxtla & & & 23.8 & 0.00 \\
Bovinos & 50 & 14 & 28.0 & $16.2-42.4$ & & \\
Búfalos & 31 & 26 & 83.8 & $66.2-94.5$ & & \\
Subtotal & 81 & 40 & 49.3 & $38.1-60.6$ & & \\
UPP 2 & Medellín & & & & \\
Bovinos & 35 & 11 & 31.4 & $16.8-49.2$ & & 0.08 \\
Búfalos & 22 & 12 & 54.5 & $32.2-75.6$ & & \\
Subtotal & 57 & 23 & 40.3 & $27.8-54.1$ & & \\
\hline Total & $\mathbf{1 3 8}$ & $\mathbf{6 3}$ & $\mathbf{4 5 . 6}$ & $\mathbf{3 7 . 1 - 5 4 . 3}$ & & \\
\hline
\end{tabular}

${ }^{*} \mathrm{IC}_{95 \%}=$ Intervalo de Confianza al 95\%. +:Positivos; F\%: Frecuencia (\%).

Con relación a los perros, $4 / 6$ resultaron positivos $(66.6 \%)$ mediante la prueba IFI. Dos cachorros y una hembra adulta presentaron anticuerpos dentro de la UPP 1 , mientras que un macho adulto resultó positivo a la misma prueba en la UPP 2.

En la Tabla 2 se observa que, de acuerdo con la especie animal, 38/53 búfalos, presentaron la mayor frecuencia con $71.6 \%$ (IC $_{95 \%} 57.6-$ 83.2). Con relación a la edad, los animales de 1-24 y 73-96 meses, resultaron con mayor presencia de anticuerpos contra $N$. caninum $52.5 \%\left(\mathrm{IC}_{95 \%} 36.12-68.4\right)$ y $50 \%\left(\mathrm{IC}_{95 \%} 28.2-\right.$
71.7), respectivamente. Para el caso del sexo de los animales, aun cuando únicamente se muestrearon machos como los sementales 7/13 resultaron seropositivos con el $53.8 \%{\text { ( } \mathrm{IC}_{95} \%}$ $25.1-80.7$ ) y en $56 / 118$ hembras con $47.4 \%$ ( $\mathrm{IC}_{95 \%}$ 38.1-56.8). De acuerdo con la Condición Corporal (CC) de los animales, la frecuencia osciló para la CC1, CC2 y CC3 entre 12.5, 50.0 y $42.1 \%$ respectivamente.

Tabla 2. Frecuencia de Neospora caninum en Bovinos y Búfalos de Agua de acuerdo con la Especie, Edad, Sexo y Condición Corporal.

\begin{tabular}{|c|c|c|c|c|c|c|}
\hline Variable & $\mathbf{n}$ & + & F\% & $* \mathbf{I C}_{95 \%}$ & $\mathbf{X}^{2}$ & $\mathbf{P}$ \\
\hline Especie & & & & & 23.5 & 0.00 \\
\hline Búfalos & 53 & 38 & 71.6 & $57.6-83.2$ & & \\
\hline Bovinos & 85 & 25 & 29.4 & $20.0-40.2$ & & \\
\hline \multicolumn{5}{|c|}{ Edad (meses) } & 3.1 & 0.67 \\
\hline $1-24$ & 40 & 21 & 52.5 & $36.12-68.4$ & & \\
\hline $25-48$ & 28 & 11 & 39.2 & $21.5-59.4$ & & \\
\hline $49-72$ & 35 & 15 & 42.8 & $26.3-60.6$ & & \\
\hline $73-96$ & 22 & 11 & 50.0 & $28.2-71.7$ & & \\
\hline $97-120$ & 11 & 5 & 45.4 & $16.7-76.6$ & & \\
\hline$>121$ & 2 & 0 & 0 & $0-84.1$ & & \\
\hline Sexo & & & & & 1 & 0.3 \\
\hline Macho & 13 & 7 & 53.8 & $25.1-80.7$ & & \\
\hline Hembra & 118 & 56 & 47.4 & $38.1-56.8$ & & \\
\hline \multicolumn{5}{|c|}{ Condición Corporal (CC) } & 4.4 & 0.1 \\
\hline 2 & 8 & 1 & 12.5 & $0.3-52.6$ & & \\
\hline 3 & 92 & 46 & 50.0 & $39.3-60.6$ & & \\
\hline 4 & 38 & 16 & 42.1 & $26.3-59.1$ & & \\
\hline Total & 138 & 63 & 45.6 & 37.1-54.3 & & \\
\hline
\end{tabular}

La Tabla 3, muestra los resultados con relación a si los animales son nacidos en las UPP, la mayor frecuencia se presentó en los nacidos 44/86 con el 51.1\% (IC I5\% $_{40.1-62.1)}$. Si los animales son vacunados, aquéllos que no lo son $41 / 61$ resultaron con la mayor frecuencia a $N$. caninum

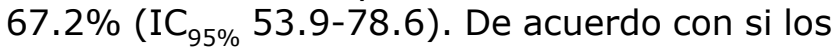
animales frecuentan y/o toman agua de represa, $38 / 53$ animales presentaron el $71.6 \%$ (IC $_{95 \%}$ 57.6-83.2). Por último, la densidad (animales por hectárea) indica que los bovinos que conviven en un espacio de 1.2 presentaron la mayor

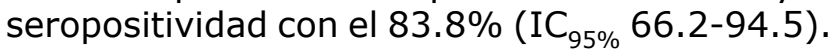


Tabla 3. Frecuencia de Neospora caninum en Bovinos y Búfalos de Agua de acuerdo con si es nacido en el rancho, vacunación, fuente de agua y a la densidad.

\begin{tabular}{|c|c|c|c|c|c|c|}
\hline Variable & $\mathbf{n}$ & + & F\% & $* \mathbf{I} \mathbf{C}_{95 \%}$ & $x^{2}$ & $\boldsymbol{P}$ \\
\hline \multicolumn{5}{|c|}{ Nacido en la UPP } & 2.7 & 0.0 \\
\hline Si & 86 & 44 & 51.1 & $40.1-62.1$ & & \\
\hline No & 52 & 19 & 36.5 & 23.6-51.0 & & \\
\hline \multicolumn{5}{|l|}{ Vacunación } & 20.4 & 0.0 \\
\hline $\mathrm{Si}$ & 77 & 22 & 28.5 & $18.4-40.0$ & & \\
\hline No & 61 & 41 & 67.2 & 53.9-78.6 & & \\
\hline \multicolumn{5}{|c|}{ Fuente de Agua } & 23.5 & 0.0 \\
\hline Represa & 53 & 38 & 71.6 & $57.6-83.2$ & & \\
\hline Corriente & 85 & 25 & 29.4 & $20.0-40.2$ & & \\
\hline \multicolumn{5}{|l|}{ Densidad } & 25.1 & 0.0 \\
\hline 1.2 & 31 & 26 & 83.8 & $66.2-94.5$ & & \\
\hline 3 & 57 & 23 & 40.3 & $27.5-54.1$ & & \\
\hline 4 & 50 & 14 & 28.0 & $16.2-42.2$ & & \\
\hline Total & 138 & 63 & 45.65 & 37.1-54.3 & & \\
\hline
\end{tabular}

${ }^{*} \mathrm{IC}_{95 \%}=$ Intervalo de Confianza al 95\%. + : Positivos; F\%: Frecuencia (\%).

\section{DISCUSIÓN}

Se ha descrito que los búfalos tienden a reflejar seroprevalencias ante $N$. caninum superiores a las reportadas en bovinos, principalmente cuando ambas especies conviven $\mathrm{y} / \mathrm{o}$ interactúan de manera frecuente $(9,12)$, lo que concuerda con las frecuencias encontradas y sistema de manejo de ambas UPP consideradas en el presente escrito. De igual manera, la frecuencia de la UPP1 es equiparable con la más alta reportada a nivel internacional en Australia con $88.3 \%$ de animales seropositivos, estudio en el que se incluyeron ambas especies (13); sin embargo, los presentes hallazgos se encuentran muy por encima de los reportados en diferentes partes del mundo como el obtenido en China de $0 \%$, Filipinas con 3.8\% (9) o Vietnam del 1.5\% (9).

En México, hasta el momento solo hay una prevalencia sérica descrita en búfalos del $24.3 \%$ en el estado de Veracruz (14). Con respecto a bovinos, la seroprevalencia encontrada en ambas UPP está por encima de lo reportado en México ya que son pocos los estudios realizados en condiciones similares; entre ellos, se reporta en el estado de Veracruz un $26 \%$ de prevalencia general incluyendo ganado lechero, de carne y sus cruzas (15) y de $20.8 \%$ en ganado de doble propósito (16). Así mismo, en el sureste se reporta un $11.6 \%$ en ganado productor de carne (17). Al analizar las fechas de publicación de los estudios antes mencionados en México, es posible considerar a la neosporosis como un problema endémico cuando menos en ganado bovino.

Sin embargo, las diferentes seroprevalencias, seropositividades o frecuencias reportadas ya sean referentes a bovinos, búfalos, cualquier hospedero de $N$. caninum u otro agente etiológico se deben revisar y comparar cuidadosamente, debido a que muchas de las pruebas indirectas empleadas no han sido estandarizadas, los puntos de corte se eligen de manera arbitraria, se han validado en hospederos diferentes, se basan en el uso de proteínas recombinantes o simplemente se emplean pruebas distintas (9). Los únicos estudios que se deben comparar son aquéllos que cumplen con alta similitud en las variables estudiadas, homogeneidad en la población y en las técnicas empleadas (18).

Si se toma en cuenta lo mencionado anteriormente, el presente estudio tiene muchas variables similares a las del estudio de 2017 de búfalos en México (14), entre los más destacables se menciona la técnica de diagnóstico empleada y la población elegida, en ambos estudios se eligió la prueba ELISA y se incluyeron animales de todas las edades, punto que puede reducir el sesgo, ya que en algunos estudios solo se consideran animales adultos (12), se ha notificado que la probabilidad de presentar anticuerpos contra $N$. caninum aumenta con el paso del tiempo (9), se ha reportado que a mayor edad aumenta la posibilidad de infección, reinfección o reactivación de esta (18), la diferencia entre las seroprevalencias descritas puede estar relacionada con la transmisión horizontal, debido al consumo de pastos y agua contaminados aquí mencionados (9). Otras de las razones por las cuales es tan notoria la diferencia entre el actual estudio y el del 2017 (14) es que en el presente se consideró el total de los animales dentro de las UPP y en el otro sólo una muestra de cada hato, además de la cercana convivencia con bovinos aquí descrita en ambas UPP la cual tiene influencia positiva sobre la presencia de anticuerpos.

Son pocos los estudios en los que se incluyen búfalos y bovinos de manera conjunta, como se mencionó anteriormente, las similitudes con el estudio australiano (13) son también 
de resaltar ya que en México es una práctica muy común mantener ambas especies en una misma propiedad, debido a las dificultades para mantenerlas por separado, la seroprevalencia descrita de 88.3 y $31.8 \%$ en búfalos y bovinos australianos, respectivamente, es muy cercana a las aquí encontradas en ambas UPP utilizando la misma prueba serológica, aunque se difiere en gran medida en el número de hatos y animales muestreados.

Por otra parte, una de las principales diferencias de esta investigación con la mayoría de los estudios de esta índole es la inclusión de caninos y su diagnóstico serológico, ya que es el hospedero definitivo de $N$. caninum $(1,4)$, variable que debiera ser considerada en todo estudio referente a neosporosis y $N$. caninum en ganado. Gran parte de los estudios solo mencionan la presencia de caninos dentro de las fincas $y$, a pesar de que ha sido referido como factor de riesgo (19), que contribuye con la diseminación de la infección o enfermedad (1) y participa de manera activa en los ciclos doméstico y silvestre (4), suele omitirse su análisis serológico en dichos estudios.

Las frecuencias encontradas de 75 y $50 \%$ en los caninos pertenecientes a las UPP uno y dos, respectivamente, demuestran contacto con el agente y la corta edad de los cachorros presentes en la UPP1 sugiere una infección vertical, sin embargo, la detección de anticuerpos no es indicativo de infección activa al momento de la toma de muestra y se hace necesaria la detección del agente o su ADN para poder demostrar la infección (20). Considerando el difícil control sobre el acceso a caninos ferales o silvestres dentro de los potreros y viendo la alta presencia de seropositividad en búfalos y bovinos hacen pensar en la existencia de un ciclo silvestre en este sistema de producción (13); por otra parte, se ha observado que las prácticas de alimentación hacia los caninos en cada UPP están íntimamente relacionadas con la posibilidad de seropositividad dentro del hato, debido al posible consumo de fetos abortados o placentas (18) a los cuales tiene libre acceso los caninos domésticos, ferales o silvestres de la zona.

Por otro lado, las condiciones climatológicas características de la zona pueden también contribuir con la seropositividad, las altas temperaturas y lluvias parecen tener un efecto benéfico sobre la esporulación de los ooquistes de $N$. caninum y su diseminación, además dichas condiciones promueven la proliferación de hongos y bacterias, que afectan al ganado y provocan que el sistema inmunológico no sea capaz de proteger adecuadamente al individuo, con lo cual puede tener lugar una reactivación de la infección en los animales infectados crónicamente (18).

Otro riesgo de infección identificado de manera reiterada en estudios de corte serológico es el compartir bebederos con otras especies y el origen el agua (21), lo que puede tener relación con la transmisión horizontal por consumo de agua contaminada con ooquistes esporulados de $N$. caninum excretados por caninos domésticos o silvestres, que también pueden contaminar las praderas y así contribuir al aumento en el riesgo de infección $(13,21)$. La predilección de los búfalos por las zonas inundables cobra también importancia gracias a que los ooquistes pueden ser arrastrados por las corrientes de agua y concentrados en los sitios de descanso y baño que atraen a los búfalos, multiplicando el riesgo de consumirlos con el agua (13) en la represa.

Por otra parte, se ha reportado que los búfalos tienen una elevada posibilidad de presentar anticuerpos anti- $N$. caninum de 3-7 veces superior a los bovinos, así como que el búfalo es resistente a la neosporosis y presenta menos signos clínicos de la enfermedad (9). Dicho fenómeno puede estar relacionado con la rusticidad del búfalo, su sistema inmunológico, edad, ruta de infección y factores externos como alimentación, manejo y atribuibles al aislado como dosis infectante o patogenicidad (1), aunque se postula que los búfalos han co-evolucionado con el parásito y desarrollado tolerancia (13); sin embargo, a pesar de su aparente resistencia a la enfermedad, ha sido posible infectar de manera experimental hembras bufalinas, producir el aborto en ellas $(22,23)$ y detectar ADN en fetos bufalinos (24).

Se ha descrito de manera reiterada que $N$. caninum puede ser transmitido de forma trasplacentaria, vertical o congénita de una madre infectada a su feto a lo largo de la preñez, ésta es la principal vía de transmisión de la infección, este parásito protozoario es uno de los organismos con mayor capacidad de transmisión vertical en el ganado, hasta un $95 \%$ de los terneros pueden nacer infectados verticalmente en una misma explotación y el parásito puede pasar de la madre al feto durante varias generaciones, las hembras infectadas serán positivas durante toda su vida, teniendo más probabilidades de presentar aborto al llegar a adultas, contribuyendo a mantener 
la infección en la explotación, los abortos y la infección pueden repetirse en un mismo animal y un alto porcentaje de los terneros nacidos de hembras seropositivas son clínicamente normales, pero pueden presentar anticuerpos contra a $N$. caninum antes de la toma de calostro $(1,18,25)$, la alta frecuencia serológica en ganado bufalino aumenta la probabilidad de transmisión horizontal dentro de ambas UPP, esta es otra de las razones por la cual la frecuencia de anticuerpos es mayor en ganado bufalino en este tipo de sistema de producción pecuario, lo antes dicho guarda una relación muy estrecha con la densidad de población pues en ganado lechero que cuenta con una elevada densidad poblacional se han reportado prevalencias y seroprevalencias superiores al $80 \%$ (26) y también se considera que los ranchos con elevado número de ganado pueden utilizar sistemas de alimentación que llegan a elevar el riesgo de transmisión horizontal, como el pastoreo, a través del consumo de alimento y agua contaminada por hospederos definitivos en regiones con alta presencia de caninos silvestres (27).

De acuerdo a estudios a nivel internacional, los hallazgos aquí descritos aportan información relevante sobre la elevada detección de anticuerpos en búfalos cuando conviven de manera cercana con bovinos y caninos, lo que supone la existencia de un ciclo silvestre en este sistema de producción; no obstante, es necesario ampliar el número de animales y UPP incluidas para poder afirmar si existe dicho ciclo en este sistema de producción donde conviven las tres especies en la zona central del estado de Veracruz, México.

En conclusión, se comprobó la presencia de anticuerpos contra $N$. caninum en población bovina, bufalina y canina de las UPP estudiadas. Se confirma que existe una mayor frecuencia de anticuerpos en búfalos de agua cuando cohabitan con bovinos y caninos, lo que podría indicar un ciclo silvestre en las condiciones de producción extensiva del sistema búfalo/bovino en la zona centro de Veracruz, México.

\section{Conflicto de intereses}

Los autores declaran que no existe conflicto de intereses de ningún tipo durante la realización y elaboración de esta investigación.

\section{Agradecimientos}

Los autores agradecen a José Alberto Blanco y Pedro Ramírez, propietarios bufaleros de las UPP por las facilidades otorgadas para la realización de éste trabajo y al Laboratorio de Parasitología en la Unidad de Diagnóstico del rancho "Torreón del Molino" de la Facultad de Medicina Veterinaria y Zootecnia de la Universidad Veracruzana por el financiamiento del proyecto.

\section{REFERENCIAS}

1. Dubey JP. Review of Neospora caninum and neosporosis in animals. Korean J Parasitol. 2003; 41(1):1-16. https://dx.doi. org/10.3347\%2Fkjp.2003.41.1.1

2. Dubey JP, Schares P. Neosporosis in animalsthe last five years. Vet Parasitol. 2011; 180:90-108. https://doi.org/10.1016/j. vetpar.2011.05.031

3. Rezvan $\mathrm{H}$, Khaki A, Namavari M, Abedizadeh R. An investigation of the concurrency of anti-Neospora antibody and parasitemia in water buffalo (Bubalus bubalis) in northwest of Iran. Vet Res Forum. 2019; 10(1):79-84. https://dx.doi.org/10.30466/vrf.2019.34314
4. Dubey JP, Jenkins MC, Rajendran C, Miska K, Ferreira LR, Martins J, et al. Gray wolf (Canis lupus) is a natural definitive host for Neospora caninum. Vet Parasitol. 2011; 181(2-4):382-387. https://doi. org/10.1016/j.vetpar.2011.05.018

5. Campanile G, Neglia G, D'Occhio MJ. Embryonic and fetal mortality in river buffalo (Bubalus bubalis). Theriogenology. 2016; 86:207-213. https://doi.org/10.1016/j. theriogenology.2016.04.033 
6. Hussain T, Babar EB, Ali A, Nadeem A, Rehman ZU, Musthafa MM, et al. Microsatellite based genetic variation among the buffalo breed populations in Pakistan. J. Vet. Res. 2017; 61(4):535-542. https://doi. org/10.1515/jvetres-2017-0057

7. Barboza JG. Bondades ecológicas del búfalo de agua: camino hacia la certificación. Tecnología en Marcha: 2011; 24(5)8288. https://revistas.tec.ac.cr/index.php/ tec marcha/article/view/167/165

8. Romero SD, Pérez LAA. Logros y desafíos de la ganadería doble propósito. Bubalinocultura en México: retos de industria pecuaria naciente. Gonzales-Stagnaro, N. MadridBury, E. Soto-Belloso (eds) Fundación GIRARZ. Ediciones Astro Data S.A: Maracaibo, Venezuela; 2014.

9. Reichel MP, Mc Allister MM, Nasir A, Moore DP. A review of Neospora caninum in water buffalo (Bubalus bubalis). Vet Parasitol. 2015; 212:75-79. http://dx.doi. org/10.1016/j.vetpar.2015.08.008

10. INAFED. Enciclopedia de los municipios y delegaciones de México. Instituto para el Federalismo y el Desarrollo Municipal, Decretaría de gobernación: México; 2020. http://siglo.inafed.gob.mx/enciclopedia/ EMM30veracruz/index.html

11. NOM-062-ZOO-1999. Norma Oficial Mexicana, Especificaciones técnicas para la producción, cuidado y uso de los animales de laboratorio. Servicio Nacional de Sanidad, Inocuidad y Calidad Agroalimentaria. SENASICA, México. 22 de agosto de 2001. https://www.gob.mx/ senasica/documentos/nom-062-zoo-1999

12. Moore DP, Konrad JL, San Martino S, Reichel MP, Cano DB, Mendez S, et al. Neospora caninum serostatus is affected by age and species variables in cohabiting water buffaloes and beef cattle. Vet Parasitol. 2014; 203:259-263. http://dx.doi.org/10.1016/j. vetpar.2014.04.011

13. Neverauskas CE, Nasir A, Reichel MP. Prevalence and distribution of Neospora caninum in water buffalo (Bubalus bubalis) and cattle in the northern territory of Australia. Parasitol Int. 2015; 64:392396. http://dx.doi.org/10.1016/j. parint.2015.05.009
14. Romero-Salas D, Alvarado-Esquivel C, Domínguez-Aguilar G, Cruz-Romero A, Ibarra-Priego N, Barrientos-Salcedo C, et al. Seroepidemiology of infection with Neospora caninum, Leptospira, and Bovine herpesvirus type 1 in water buffaloes (Bubalus bubalis) in Veracruz, México. Eur J Microbiol Immunol. 2017; 7(4):278-283. http:// dx.doi.org/10.1556/1886.2017.00029

15. Romero-Salas D, García-Vázquez Z, MontielPalacios F, Montiel-Peña T, Aguilar-Domínguez M, Medina-Esparza L, et al. Seroprevalance of Neospora caninum antibodies in cattle in Veracruz, México. J Anim Vet Adv. 2010; 9(10):1445-1451. http://dx.doi. org/10.3923/javaa.2010.1445.1451

16. Montiel-Peña T, Romero-Salas D, GarcíaVázquez Z, Medina-Esparza L, Cruz-Vázquez C. Neosporosis bovina en ranchos ganaderos de la zona norte del estado de Veracruz, México. Trop subtrop agroecosystems. 2011; 13:469-479. http://www.revista. ccba.uady.mx/ojs/index.php/TSA/article/ view/1387/686

17. García-Vázquez Z, Rosario-Cruz R, MejíaEstrada F, Rodríguez-Vivas I, RomeroSalas D, Fernández-Ruvalcaba $M$, et al. Seroprevalence of Neospora caninum antibodies in beef cattle in three southern states of México. Trop Anim Health Prod. 2009; 41:749-753. http://dx.doi. org/10.1007/s11250-008-9247-x

18. Dubey JP, Schares G, Ortega-Mora LM. Epidemiology and control of neosporosis and Neospora caninum. J Clin Microbiol. 2007; 20:323-367. http://dx.doi.org/10.1128/ CMR.00031-06

19. Sánchez F, Morales E, Martínez J, Trigo F. Determination and correlation of antiNeospora caninum antibodies in dogs and cattle from México. Can J Vet Res. 2003; 67:142-145. https://www.ncbi.nlm.nih.gov/ pmc/articles/PMC227043/

20. Almería S. Neospora caninum and wildlife. ISRN Parasitol. 2013; 947347. http:// dx.doi.org/10.5402/2013/947347 
21. Sierra RC, Medina-Esparza L, Parra MR, García-Vázquez Z, Cruz-Vázquez C. Factores de riesgo asociados a la seroprevalencia de anticuerpos a Neospora caninum en ganado lechero de Aguascalientes, México. Rev Méx Cienc Pec. 2011; 2(1):15-24. https:// cienciaspecuarias.inifap.gob. $\mathrm{mx} / \mathrm{index}$.php/ Pecuarias/article/view/1457/1452

22. Chryssafidis $A L$, Cantón $G$, Chianini $F$, Innes EA, Madureira EH, et al. Abortion and foetal lesions induced by Neospora caninum in experimentally infected water buffalos (Bubalus bubalis). Parasitol Res. 2015; 114(1):193-199. http://dx.doi. org/10.1007/s00436-014-4178-0

23. Konrad JL, Moore DP, Crudeli G, Caspe SG, Cano DB, Leunda MR, et al. Experimental inoculation of Neospora caninum in pregnant water buffalo. Vet Parasitol. 2012; 187(12) : 72-78. https://doi.org/10.1016/j. vetpar.2011.12.030

24. Auriemma $C$, Lucibelli MG, Borriello $G$, De Carlo $E$, Martucciello A, Schiavo $L$, et al. PCR detection of Neospora caninum in water buffalo foetal tissues. Acta Parasitol. 2014; 59(1):1-4. https://doi.org/10.2478/ s11686-014-0201-y
25. Chryssafidis $A L$, Cantón $G$, Chianini F, Innes EA, Madureira EH, Gennari SM. Pathogenicity of Nc-Bahia and Nc-1 strains of Neospora caninum in experimentally infected cows and buffaloes in early pregnancy. Parasitol Res. 2014; 113(4):1521-8. http://dx.doi. org/10.1007/s00436-014-3796-x

26. Reyes-Sandoval RM, Álvarez-Martínez JA, Rojas-Martínez C, Espinosa-Ayala E, GarcíaRubio VG, Ojeda-Carrasco JJ. Detección de Neospora caninum por PCR anidada en leucocitos de bovinos productores de leche. Ecosist. Recur. Agropec. 2017; 4(12)563570. http://dx.doi.org/10.19136/era. a $4 n 12.1288$

27. Barling KS, Sherman $M$, Peterson MJ, Thompson JA, Mc Neill JW, Craig TM, Adams LG. Spatial associations among density of cattle, abundance of wild canids, and seroprevalence to Neospora caninum in a population of beef calves. J. Am. Vet. Med. Assoc. 2000; 217(9)1361-1365. http:// dx.doi.org/10.2460/javma.2000.217.1361 